\title{
A concepção da infância e os crimes contra a dignidade sexual
}

\author{
Childhood conception and crimes against sexual dignity
}

Denise Vichiato Polizelli ${ }^{1}$

\section{Resumo}

O reconhecimento da infância como fase obrigatória e natural do desenvolvimento humano é construção recente, o que se reflete diretamente na tutela dos direitos infanto-juvenis. A concepção de infância e o reconhecimento dela em todas as crianças, indistintamente, são essenciais para a efetiva proteção da dignidade sexual, por ser determinante para a interpretação correta da lei. É feita uma análise sobre as figuras da vítima e do agressor, que estarão sujeitas à aplicação da lei. Ainda, se mostra fundamental o estudo dos crimes sexuais a partir do tipo penal revogado, a fim de, compreendendo melhor o legislador, interpretar o estupro de vulnerável com olhos na efetiva proteção da dignidade sexual.

Palavras Chave: Concepção de infância; Vítima; Agressor; Estupro de vulnerável; Dignidade sexual.

\section{Abstract}

Acknowledgment of childhood as mandatory and natural stage of human being development is a recent construction, which directly impacts the protection of child/youth rights. The conception of childhood and its indiscriminate acknowledgment in all children are essential for effective protection of sexual dignity by being key factors for correct law interpretation. An analysis is made on victim and offender roles, which will be subject to law enforcement. Also, the study on sexual crimes is essential from revoked crime definition to, by better understanding the lawgiver, interpret the rape of vulnerable ones aiming at the effective protection of sexual dignity.

Keywords: Childhood conception; Victim; Offender; Rape of vulnerable ones; Sexual dignity.

\footnotetext{
${ }^{1}$ Graduada em Direito pela Universidade Estadual de Londrina. Pós-Graduanda em Direito e Processo Penal. depolizelli@yahoo.com.br
} 


\title{
Introdução
}

A origem histórica dos crimes sexuais está dissociada da concepção de infância, já que se trata de uma construção histórica recente, motivo pelo qual não se considerava necessário a previsão de tutela específica para os direitos infanto-juvenis. Assinala ARIÈS (1981, p. 51, apud CALDEIRA) que "até o fim do século XIII, não existem crianças caracterizadas por uma expressão particular, e sim homens de tamanho reduzido". No mesmo sentido, HEYWOOD (2004, p. 23, apud CALDEIRA) afirma que "a "descoberta" da infância teria de esperar pelos séculos XV, XVI e XVII, quando então se reconheceria que as crianças precisavam de tratamento especial". Entretanto, a concepção de infância como período de educação e formação é contemporânea do século XX (GABEL, 1997, p. 29).

Sendo assim, em análise histórica da legislação sexual, nota-se que a proteção da infância e adolescência era uma consequência da tutela ao corpo feminino, também enquanto propriedade do homem, devido ao sistema patriarcal.

A história dos crimes sexuais está intimamente relacionada com aquilo que é considerado padrão vigente na sociedade, assim como a liberdade de expressar sua sexualidade, principalmente no que diz respeito ao controle imposto às mulheres e filhos, relevando toda a dinâmica social quanto à repressão.

\begin{abstract}
Por trás da utilização das formas de controle social da sexualidade, como forma de repressão, estão sempre ocultas as relações de poder, tais como o controle social da religião sobre os fieis, do Estado sobre os cidadãos, dos pais sobre os filhos, dos homens sobre as mulheres etc. isso porque o exercício do poder de repressão da sexualidade não apresenta suas conseqüências somente em relação à conduta sexual individual. Também reflete na maneira pela qual as instituições crescem e se desenvolvem (GRECO e RASSI, 2010, p. 08).
\end{abstract}

Sobre o tema, Prado (2008, p. 637) observa que o direito romano (800-450 a.C.) entendia como estupro qualquer ato impudico, sem qualquer especificação quanto aos sujeitos ativo ou passivo, englobando o adultério e a pederastia, de pena capital. $\mathrm{O}$ crime era próprio na hipótese de a vítima ser virgem, do contrário, impróprio, e qualificado se houvesse violência, fraude e sedução.

A partir dos séculos XII e XIII, o casamento foi considerado sacramento e a Igreja Católica passou a interferir diretamente na estrutura social, com o intuito de abolir uniões entre indivíduos de uma mesma família. O comportamento sexual era permitido na 
constância do casamento, exclusivamente para a procriação, e também para afastar os homens de outros vícios, como a zoofilia, a homossexualidade, a masturbação, e finalmente o incesto e a pederastia.

Muitas legislações previam como pena do estupro a obrigação de se casar com a vítima mulher virgem, a exemplo das Ordenações Filipinas (1603-1916) e do Código Criminal do Império (1830), que exigiam a constituição de dote. A preocupação, no entanto, não era proteger a vítima, mas dar amparo ao sistema patriarcal, tutelando o direito do pater sobre mulher e filhos. Também o Código Penal de 1890 não apresentava maiores especificidades sobre o universo infantil.

Nota-se, portanto, que no Brasil, a primeira legislação a contemplar proteção especial à criança no âmbito sexual foi o Código Penal de 1940, vigente até a presente data, que sofreu pontual modificação sobre o tema recentemente. O estudo se volta para uma análise sobre a vítima, o autor e a lei em duas fases, revogada e em vigência, a fim de compreender se a norma se presta a tutelar o bem jurídico tutelado.

\section{A vítima}

A fim de compreender melhor o processo de vitimização da criança, diversos estudos americanos publicados recentemente analisam o discurso dos agressores que perpetraram abusos sexuais (Gabel, 1997, p. 56). Neste ínterim, a pesquisa de Conte, Wolf e Smith (1989), em amostragem de 20 adultos que abusaram sexualmente de crianças, os interrogaram sobre o critério de escolha da vítima, a forma pela qual se engajam e mantêm essas crianças em situações de abuso sexual.

Quando questionados sobre a escolha da criança, dentre várias possíveis, as respostas denotaram capacidade de escolher aquelas vulneráveis: por serem mais jovens (e não falariam sobre o abuso); ou aquelas das quais as pessoas zombam (com pouca credibilidade); a que parecer mais carente (não hesitará tanto na aproximação); muito amigável com adultos. Além disso, há uma preferência por aquelas que já foram vítimas ou que são, por natureza, mais submissas. 
Conforme observa Gabel (1997, pgs. 30/31), pesquisas realizadas na região de Rhône-Alpes ${ }^{2}$ (França, 1989) apontam que 6,2\% dos entrevistados declararam ter sido vítimas de um ou vários abusos antes dos dezoito anos. Na população feminina, o número é superior, representando $7,8 \%$ do total de mulheres. No mesmo sentido, uma abordagem com universitários de Paris e região ${ }^{3}$ apontam que $8 \%$ das mulheres e $7 \%$ dos homens afirmam que foram vítimas de pelo menos um desses eventos: assédio sexual, estupro, ou incesto.

Estas pesquisas também apontam resultados idênticos no tocante à idade do primeiro abuso, a média de $55 \%$ dos estudantes afirmou que este se deu entre dez e dezesseis anos de idade (GABEL, 1997, p. 36).

A metade dos primeiros abusos é perpetrada antes dos doze anos entre os meninos e antes dos onze anos entre as meninas; o número máximo de ocorrências se situa, para ambos os sexos, em torno da puberdade. Entretanto, é possível que os entrevistados não se lembrem de abusos sofridos em tenra idade, já que, conforme apontam estudos, $25 \%$ dos casos acontece antes dos oito anos de idade, e 33\% das crianças enviadas aos hospitais por abusos sexuais tinham menos de seis anos de idade (Gabel, 1997, p. 37), conforme aponta o gráfico abaixo.

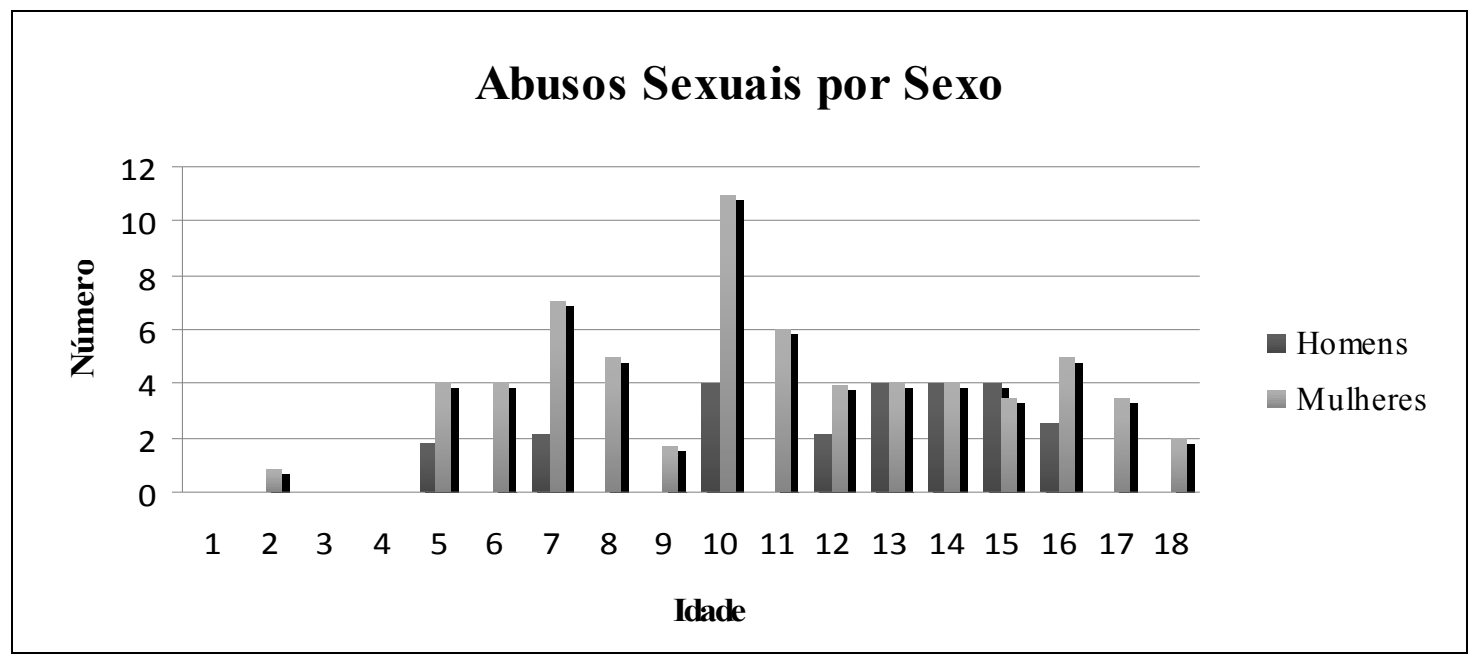

\footnotetext{
2 Pesquisa feita pelo Projeto Regional de Observação das Moléstias Sexualmente Transmissíveis (PROMST) em abril/maio de 1989, junto a uma amostragem de 1.511 pessoas, representativas da população entre 18 e 59 anos na região Rhône-Alpes (segundo idade, sexo, categoria socioprofissional e de localização geográfica). Trabalho confiado ao instituto de pesquisa BVA.

3 Pesquisa realizada pelo Centro de Pesquisa sobre a Infância e a Adolescência (CREA) em maio/junho de 1988, junto a uma amostragem representativa de mil estudantes do primeiro e segundo ano da universidade. Trabalho de campo e análise estatística realizada pelo Instituto Francês de Estudos e Análises (IFEA).
} 
Sobre os números no Brasil, Teixeira (2001) aponta que uma pesquisa realizada a partir de 168 casos de abuso sexual doméstico sofrido por crianças e adolescentes conclui que mais de $60 \%$ dos casos atingiram crianças entre 7 e 13 anos de idade, sendo que em $20,2 \%$ as vítimas tinham menos de 6 anos, e 18,5\% da violência sexual era direcionada à faixa etária de 14 a 18 anos. A autora, ao final, faz uma observação preocupante: "Apesar desses dados referirem-se a vitimização sexual intrafamiliar, sabemos que também na exploração sexual comercial os adultos preferem as meninas mais novas".

Se, por um lado, a opinião geralmente se mostra mais sensível aos abusos com as crianças, símbolo de inocência e pureza, existe a propensão a minimizar os efeitos do abuso nos adolescentes. Porém, já está amplamente provado que o adolescente é muito frágil, pois é nesta fase, caracterizada pela entrada para a maturidade, que o indivíduo passa por um período de crise que se caracteriza pela reviravolta na vida pessoal e interpessoal, a fim de reorganizar as relações com os outros, consigo mesmo e com o próprio corpo. É também nesta fase que ocorrem as primeiras relações sexuais e todas as dificuldades que lhes são associadas. As agressões sexuais em adolescentes podem provocar graves perturbações, como fobias e problemas sexuais, que podem culminar em fugas, tentativas de suicídio ou suicídio efetivo, além de fobia ao sexo oposto ou a relacionamentos no geral, ou ainda aversão ao ato sexual ou sua exacerbação.

Quando o assunto é prostituição infanto-juvenil, no Brasil existem diversas formas de exploração sexual de menores de 18 anos. Em primeiro lugar, pode-se elencar o turismo sexual organizado em uma rede transversal (rede hoteleira, agências de turismo, comércio de pornografia e rede de taxistas). Ainda, uma segunda forma de exploração sexual:

\footnotetext{
A segunda é a exploração de crianças e adolescentes em regiões de garimpo e prostíbulos fechados, onde a prostituição está relacionada a um mercado regionalizado, com práticas extrativistas como, por exemplo: escravidão, cárcere privado, venda (pelos pais) e tráfico de crianças e adolescentes para os garimpos ou regiões de fronteiras (MURTA e AMARAL, 2008).
}

Em terceiro lugar está o turismo náutico em rios navegáveis na região Norte e fronteiras do Centro-Oeste, e atende aos turistas e aos consumidores ribeirinhos. Por fim, o abuso no seio da família, que acontece em todas as classes sociais.

Destas quatro hipóteses levantadas por Murta e Amaral (2008), parece que somente a última causava repulsa suficiente na sociedade a ponto de a vítima não ser 
considerada culpada de sua violência. Corroborando tal informação, Teixeira (2001) aponta que, quando o assunto é prostituição infanto-juvenil, o consumidor não tem pudores ao procurar pelos serviços sexuais infanto-juvenis, já que:

\begin{abstract}
Parece não existir constrangimento algum do explorador, na abordagem e iniciação dessas meninas no comércio sexual. Uma atitude que encontra respaldo em certos setores da sociedade, cuja cumplicidade é patente. A dos motéis, por exemplo, cuja conivência, tão "natural" nesse cenário urbano, torna-se inquestionável e facilmente compreensível inclusive pelas próprias meninas. Trata-se de uma omissão sustentada por interesses econômicos, alheia a qualquer reflexão ética.
\end{abstract}

E então, verificada a ocorrência da violência sexual, ao se analisar a norma que poderia impedir o continuísmo desta realidade, mesmo diante da inexistência de qualquer requisito quanto à idoneidade moral da vítima, ainda que menor de 14 anos, pela ótica da redação anterior, a tutela não poderia ser efetiva, por se tratar de ofendida com "comprovada experiência sexual".

Para completar o perfil da vítima de crimes sexuais, segundo informações da Coordenadora Nacional do Disque 100, Leila Paiva, ao Fantástico ${ }^{4}, 83 \%$ das vítimas de violência sexual são do sexo feminino, o que demonstra claramente a existência de uma violência de gênero.

\title{
O agressor
}

A referida pesquisa Rhône-Alpes revelou que $37 \%$ dos autores de violência sexual são desconhecidos da vítima, sendo que $17 \%$ deles pertencem ao círculo familiar. Já nos Estados Unidos, conforme aponta o estudo da Children Service Division (1987) indica que $25 \%$ dos ataques são perpetrados por um membro da família; em média, um a cada seis autores é desconhecido de suas vítimas.

Já no Brasil, $80 \%$ das vítimas de abuso sexual infantil conhecem seus abusadores, sendo que desse grupo, $68 \%$ é membro da própria família, $80 \%$ são homens e $20 \%$ são mulheres. $75 \%$ dos casos ocorrem entre pai e filha (considerando outras figuras paternas,

\footnotetext{
4 DISQUE 100 recebe denúncias de abusos contra criança: Mãe batia nas filhas com vassoura e até uma pá de lixo. Veja como denunciar abuso contra crianças e adolescentes em todo país. Disponível em:

<http://fantastico.globo.com/Jornalismo/FANT/0,,MUL1595224-15605,00

DISQUE+RECEBE+DENUNCIAS+DE+ABUSOS+ CONTRA+CRIANCAS.

html>. Acesso em: 25 maio 2010.
} 
como padrastos ou companheiro da genitora) (SEABRA). Corroborando tais dados, uma pesquisa realizada em Ponta Grossa revela como principais abusadores os familiares, sendo o pai em cerca de $25 \%$, o padrasto em quase $35 \%$, o tio em quase $10 \%$ e o avô em mais de 5\% dos casos, segundo dados fornecidos pelo SIPIA (Sistema de Informação para Infância e Adolescência), conforme dados a seguir (RIBEIRO e MARTINS, 2008, p. 88).

\section{Autores da Violência}

Sexual

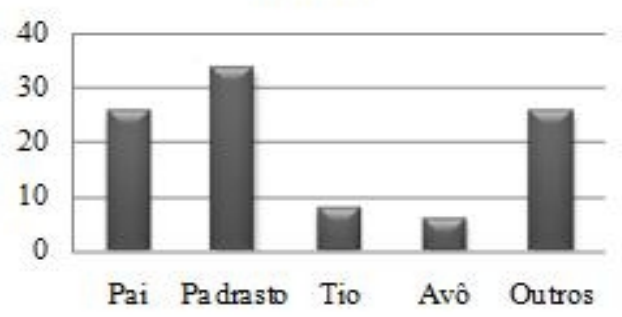

Importante considerar que o sistema jurídico brasileiro encontra-se impregnado de um conceito de autor estereotipado, entretanto, conforme demonstra o resultado de estudos norte-americanos realizados por Finkelhor e Hotaling (1983, 1984 e 1987), trata-se de jovens, na faixa etária de vinte a trinta anos, conhecidos das crianças e que lhes despertam simpatia, e em $2 / 3$ dos casos há uma aproximação real entre o autor do abuso e sua vítima (GARBEL, 1997, p. 39).

\section{Crimes sexuais: legislação anterior}

Os crimes sexuais eram apresentados sob a rubrica "Dos Crimes Contra os Costumes", título que não apresentava qualquer denominação quanto à proteção da autodeterminação sexual, muito pelo contrário, coloca como bem jurídico tutelado "os costumes", ou seja, o comportamento socialmente aceito e adequado, representando uma visão vetusta dos hábitos medianos e até puritanos da moral vigente, sob o ângulo da generalidade das pessoas, apesar de inexistirem parâmetros para nortear o foco dos denominadores comuns (NUCCl, 2009, p. 11). 
Neste sentido, a doutrina preocupava-se com o estabelecimento de conceitos que pudessem nortear a aplicação das normas protetoras dos costumes, que eram permeados por aspectos machistas e preconceitos morais.

Não há dúvidas de existirem grandes diferenças entre o estupro de mulher honesta e o de prostituta. Se a distinção é de ser feita, no campo da cominação da pena, faz-se necessário atente o julgador para essa minorante natural, o que se fará dentro dos princípios do art. 42, C. Penal (MESTIERI, 1982, p. 33)

Desta forma, para que o ofendido de um crime sexual fosse considerado vítima, seu comportamento deveria ser revestido de inocência, pureza e moral ilibada, excluindo, portanto inúmeras hipóteses da tutela da norma. Mais especificamente, tratando-se de infância e adolescência, é comum excluir a vítima da própria condição de vulnerável, como se adulto fosse. Ou seja, a norma visa proteger uma criança ou um adolescente, mas ao identificar neste, desvios causados por reiterados abusos praticados pelos adultos, lhe é ceifada a condição de vítima.

A proteção aos direitos sexuais infanto-juvenis era feita através da combinação do art. $213^{5}$ com o art. $224^{6}$, ambos do Código Penal. Na alínea a deste último dispositivo constava previsão de hipótese em que presumia a violência quando a vítima contasse com menos de 14 anos na data do fato. Tratava-se de circunstância que elidia a exigência do efetivo constrangimento da vítima pela agressão à sua integridade física ou à grave ameaça para a prática sexual.

Apesar de indiscutível intenção do legislador em proteger com afinco esta categoria de vítimas, o reflexo da ausência de uma concepção de infância universal transformava crianças abusadas e prostituídas em adultos maduros suficientes para exercer sua sexualidade, ou ainda, de vítimas a libertinas. Tal raciocínio foi construído pela doutrina e a jurisprudência, que relativizaram a aplicação da norma, que se tornou iuris tantum, admitindo-se prova em contrário no tocante à vítima aparentar comportamento e

\footnotetext{
${ }^{5}$ Art. 213 - Constranger mulher à conjunção carnal, mediante violência ou grave ameaça: Pena - reclusão de seis a dez anos. (REVOGADO)

${ }^{6}$ Art. 224 - Presume-se a violência, se a vítima:

a) não é maior de catorze anos;

b) é alienada ou débil mental, e o agente conhecia esta circunstância;

c) não pode, por qualquer outra causa, oferecer resistência. (REVOGADO)
} 
compleição física superiores à referida idade, ou seja, dissociando o ofendido de sua condição de criança ou adolescente, mais ainda, de vulnerável.

Prado (2008, p. 676), concordando com tal posicionamento, alega ser impossível se estabelecer um critério etário para a autodeterminação sexual de uma pessoa, constituindose uma afronta à lógica e ao bom senso, ainda fundamentando que "a partir de uma idade legalmente fixada esta pode livremente decidir sobre sua vida sexual, mas se encontra proibida de fazê-lo às vésperas de tal fator temporal". Existe ainda a argumentação de que os adolescentes com a referida idade limite teriam suficiente capacidade fisiológica e psicoética para se autodeterminarem.

É uma questão polêmica, que merece uma análise cuidadosa.

Então, é de se questionar se a prática sexual por crianças e adolescentes em fase de puberdade não constituiria um atentado aos costumes, já que não se pode olvidar da antiga nomenclatura do Título VI, cuja tutela não se direcionava à liberdade sexual em si, mas ao comportamento socialmente aceito.

A relativização demasiada da violência presumida leva a outro questionamento: qual é o direito que a norma visava proteger? O objetivo é de fato tutelar a autodeterminação de garotas entre 12 e 13 anos, permitindo o livre exercício de sua liberdade sexual, por se julgarem maduras; ou, muito pelo contrário, daria aos homens o direito de praticar sexo com adolescentes, para satisfazerem sua lascívia sem incorrer em crime?

Tendo em vista os dados apresentados anteriormente sobre as características dos autores e das vítimas, pode-se concluir-se que não há o que discutir sobre exercício do direito à liberdade sexual quando o principal abusador é pessoa que faz parte da convivência familiar da vítima.

Gabel (1997, p. 88) ainda observa que o abusador pode negar a existência do abuso, independentemente da idade da vítima, sob o pretexto de um pretenso "direito ao prazer e à sexualidade" das crianças, mas adverte que este posicionamento despreza o sofrimento psicológico das crianças e coloca habilmente em evidência o prazer da criança em vez do prazer do adulto, que é o único que se busca na realidade.

Se a hipótese for outra, de criança ou adolescente prostituído, Gusmão (1981, p. 126/127) observa que o sistema, na verdade, defende o autor, observando que "os códigos 
hodiernos com os seus preceitos imperativos quiseram constranger os juízes a declarar culpado de violência carnal mesmo aquele que haja cedido a uma jovem exercendo público meretrício", como se a vítima, nesses casos, precisasse seduzir seu agressor para incitá-lo à prática sexual. Ele ainda acrescenta que, ao contrário do que se entende, o agente deve se esforçar para saber qual a real idade da vítima, sendo que a ignorância não poderia ser aceita como justificativa ou escusa, por se tratar de uma cômoda credibilidade passiva.

Mestieri (1982, p. 32) sustenta, em geral, não subsistir a presunção nos casos de menor corrompida. Contrariando tal posicionamento, é de se ressaltar que o tipo penal, em momento algum, exige como requisito a virgindade, honestidade, ou até mesmo idoneidade moral do ofendido. Por se tratar de criança ou adolescente já prostituída, a violência é evidente somente pelo fato de ter tido sua iniciação sexual prematuramente.

Este entendimento foi compartilhado pela Constituição Federal, que estabeleceu o princípio da proteção integral em seu artigo $227^{7}$, que dispõe que é dever de todos assegurar à criança e ao adolescente seus direitos, inclusive a dignidade, o que, por si só, já impõe ao agente ativo o dever de informar-se quanto à idade da vítima, sendo responsável criminalmente pela prática sexual perpetrada, ainda que supostamente consentida.

\begin{abstract}
A violência se presume em razão da idade da vítima, que na época dos fatos possuía apenas 12 (doze) anos, e, em tese, não possui maturidade para consentir a conveniência ou não de adotar determinada postura em matéria de sexualidade, consoante prevê o art. 224, alínea "a", do Código Penal. Portanto, não cabe falar em cópula consensual se a mulher conta com menos de 14 anos de idade, é alienada mental ou encontra-se em situação que não possa oferecer resistência.

Registro que, apesar da presunção da violência não ser absoluta, no entendimento majoritário da doutrina criminal, no caso dos autos, o réu, homem maduro e com família constituída, tinha plena ciência da idade da vítima, a qual informou que o processo de sedução começou tempos antes, quando ela tinha ainda apenas 11 anos de idade e, caso tenha ela demonstrado interesse por ele, tal é decorrente de sua pouca idade e, em especial, na idade em que as crianças desenvolvem sua sexualidade, porém não possuem maturidade suficiente, nem consciência de seus atos.

De qualquer sorte, no dia em que ocorreu a conjunção carnal, a vítima foi levada a um motel, onde permaneceu cerca de duas horas com o acusado, até o momento em que ela cedeu a investida sexual, porque o réu estava ficando zangado, em razão da negativa da menina. ${ }^{8}$
\end{abstract}

\footnotetext{
É dever da família, da sociedade e do Estado assegurar à criança e ao adolescente, com absoluta prioridade, o direito à vida, à saúde, à alimentação, à educação, ao lazer, à profissionalização, à cultura, à dignidade, ao respeito, à liberdade e à convivência familiar e comunitária, além de colocá-los a salvo de toda forma de negligência, discriminação, exploração, violência, crueldade e opressão.

${ }^{8}$ BRASIL. Tribunal de Justiça do Estado do Rio Grande do Sul. Apelação Crime № 70029688942 (Sétima Câmara Criminal). Apelante: Marcos Antônio Santana Silva. Apelado: Ministério Público. Relator: Naele Ochoa
} 
Conforme entendeu o Tribunal de Justiça do Rio Grande do Sul, a vítima de tenra idade não possui maturidade suficiente para compreender a seriedade do ato praticado, ainda que haja uma pseudo-anuência para a prática sexual.

\section{Crimes sexuais: Legislação Atual}

Inaugurando uma nova concepção quanto à liberdade sexual do indivíduo, o Código Penal ostenta em seu Título VI a denominação "Dos Crimes Contra a Dignidade Sexual”.

Estefam (2009, p. 16/17), registra que a necessidade de se reformar o Título VI do Código Penal surgiu com a promulgação da atual Constituição Federal, que erigiu a dignidade da pessoa humana como fundamento da República Federativa do Brasil. O autor ainda observa que a sexualidade deve ser pensada dentro do espaço da pessoa humana, sendo descabidos parâmetros éticos e de moralidade pública. Assim, com esta nova denominação, fica claro que se busca garantir, além da dignidade humana, a liberdade de escolha de parceiros e da relação sexual, a salvo de exploração, a intangibilidade ou indenidade sexual, além do pleno e sadio desenvolvimento da personalidade, no que se refere à sexualidade do indivíduo (p. 19).

Deste modo, tutelando-se a dignidade sexual do indivíduo, busca-se proteger sua identidade e aquilo que há de ético e moral para cada um, não havendo mais o que se questionar ou discutir quando à moral da vítima para relativização da aplicação da norma.

O tipo penal estupro de vulnerável, previsto pelo artigo 217-A do Código Penal ${ }^{9}$ foi a maior evolução apresentada pela Lei 12.015/2009. Trata-se da instituição de uma nova conduta típica com a finalidade de tutelar a dignidade sexual daqueles que possuem menor capacidade de resistirem à violência.

Piazzeta. Porto Alegre, 29 abr. 2010. Grifo nosso.

9 Art. 217-A. Ter conjunção carnal ou praticar outro ato libidinoso com menor de 14 (catorze) anos: Pena - reclusão, de 8 (oito) a 15 (quinze) anos.

$\S 1^{\circ}$ Incorre na mesma pena quem pratica as ações descritas no caput com alguém que, por enfermidade ou deficiência mental, não tem o necessário discernimento para a prática do ato, ou por qualquer outra causa, não pode oferecer resistência.

$\S 2^{\circ}$ VETADO

$\S 3^{\circ}$ Se da conduta resulta lesão corporal de natureza grave:

Pena - reclusão, de 10 (dez) a 20 (vinte) anos.

$\S 2^{\circ}$ Se da conduta resulta morte:

Pena - reclusão, de 12 (doze) a 30 (trinta) anos. 
Trata-se de tutela penal diferenciada, que se direciona às pessoas que não são capazes de externar consentimento racional e seguro para a prática sexual. Independentemente da ocorrência de violência física, já que "teria ocorrido uma coação psicológica, diante do estado natural de impossibilidade de compreensão da seriedade do ato realizado" (NUCCl, 2009, p. 34).

Nucci (2009, p. 35) considera como vulnerável aquele que é passível de lesão, despido de proteção. Pode ser pessoa enferma, deficiente mental, sem discernimento para a prática sexual, ou que por qualquer outra causa esteja incapacitado de oferecer resistência.

A conduta típica identifica-se com aquela do artigo 213, entretanto, o sujeito passivo é pessoa vulnerável por contar com menos de 14 anos, ser doente ou deficiente mental a ponto de não apresentar discernimento sexual, ou estiver impossibilitado de oferecer resistência, independente da causa. Apesar de o bem jurídico tutelado teoricamente ser o mesmo, dá-se ênfase, em razão das circunstâncias da vítima, ao pleno desenvolvimento das pessoas vulneráveis.

Outra questão de relevância é a exigência do conhecimento da condição de vulnerabilidade do ofendido por parte do ofensor. Quando foi comentada a presunção de violência que vigorava na norma revogada, apresentou-se o posicionamento de um autor no sentido de que o agente não pode ficar, como ignorante da idade da vítima, por exemplo, em uma situação confortável, que irá operar em seu favor (Gusmão, 1981, p. 127). Parece tratar-se de uma hipótese de dolo eventual, já que, considerando que esta modalidade dolosa traduz o pensamento do agente que, diante da dúvida, prefere assumir o risco de praticar o ato a preocupar-se em verificar a condição vulnerável do ofendido.

Não é o caso de se defender uma "presunção de violência absoluta", o que inclusive seria desproporcional. É notável o esforço do legislador em se fazer entender, diante de tantas interpretações distorcidas que a norma anterior apresentava. Não é porque a vítima apresenta "experiência sexual comprovada" (Nucci, 2009, p. 37) que em algum momento ela consentiu ou possui capacidade para compreender o significado do ato. Muito pelo contrário, se forem considerados, conforme apresentado anteriormente, que $80 \%$ da violência sexual ocorre entre conhecidos, e deste universo, 75\% entre a figura paterna e a filha (SEABRA), a conclusão obrigatória é que não se trata de uma opção da vítima, mas uma coação do agressor. 
Nucci $(2009$, p. 37) defende a ideia que, uma vez que o Estatuto da Criança e do Adolescente define como limite da infância os 12 anos, somente os crimes perpetrados contra vítimas que contassem com até esta idade deveriam contar com a presunção da violência absoluta. Completados 12 anos, a proteção não deveria ser tão rígida, aplicando-se relativamente, demandando uma análise de cada caso. Contrários a este posicionamento, observam Greco e Rassi (2010, p. 151).

As alterações do Código, mantendo a idade de 14 anos, não acompanharam o conceito de criança do Estatuto da Criança e do Adolescente, no qual a idade da criança vai somente até 12 anos. As leis são autônomas e, portanto, não tem influência recíproca.

Ademais, aplicar tal entendimento como regra seria distorcer a lei, que em nenhum momento estabeleceu níveis de presunção de violência, aliás, sequer faz uso desta nomenclatura. Anteriormente, foi dito que o bem jurídico tutelado é a liberdade sexual com ênfase na condição de desenvolvimento da vítima, entretanto, é de se observar, neste momento, que o Capítulo I, no qual está inserido o art. 213, é denominado de "Dos Crimes Contra a Liberdade Sexual". Já o Capítulo II, que introduz o art. 217-A, apresenta-se por "Dos Crimes Sexuais Contra Vulnerável", o que leva à interpretação de que se deve considerar, somente em último caso, a prática sexual com menor de 14 anos como exercício do direito à liberdade sexual.

Ademais, é de se ressaltar que nem a Constituição Federal nem o Estatuto da Criança e do Adolescente prevêem "direito à sexualidade" para crianças e adolescentes, devendo prevalecer a proteção à dignidade e ao desenvolvimento sadio e harmonioso.

A norma e sua interpretação estão voltadas para proteger a vítima, que no caso, é uma pessoa vulnerável, o que significa que todos os cuidados devem ser tomados para que a tutela seja efetiva e eficaz. No caso de crianças e adolescentes, a violação sexual atinge gravemente a construção da personalidade, uma vez que "demandam proteção especial em razão da sua particular vulnerabilidade, quando comparados aos adultos, própria condição peculiar da pessoa humana em desenvolvimento" (CURY, 2008, p. 901)

Neste contexto, é interessante observar que a correta aplicação da norma deve ser capaz de traçar a diferença entre vítima prostituta e prostituída, principalmente no intuito 
de se verificar se o ofendido possa se encontrar em situação de risco ${ }^{10}$, a fim de estabelecer uma ponte entre a proteção do Estatuto da Criança e do Adolescente e o Código Penal.

Diante deste cenário, faz-se necessário reconhecer a situação de vitimização vivida pela vítima, o que não significa uma redundância, mas a efetivação de uma proteção que se mostrava virtual. Somente assim, os ofendidos podem ser despidos de uma idealização de inocência e pureza, para não tolerar a prática sexual violência, sob pena de a mudança legislativa não ter provocado alterações concretas no contexto social, por não tutelar efetivamente a dignidade sexual das vítimas.

\section{Conclusão}

A infância, como produto da construção histórica, foi sendo construída pelas artes, tal qual a literatura e a pintura, assim como pelas ciências humanas, como a psicologia e a filosofia. Ghiraldelli (2000) aponta que, na tentativa de se demonstrar quais os elementos essenciais para um "menino de verdade", Carlo Collodi construiu a personagem de Pinóquio, sendo de ele exigido ser bom para seu pai e para com os outros, ter responsabilidade, ter sua própria consciência.

A concepção de infância, que exige a pureza, a inocência e a beleza, equiparando a criança a um ser angelical, pode acabar por excluírem muitas delas por estarem despidas destas características.

Entretanto, é sempre necessário lembrar que ao lidar com crianças vítimas de qualquer tipo de violência, não se está tratando de modelos ou anjos infantis, mas sim de pessoas em desenvolvimento, que independentemente do que se tenha por conceito de infância, este deve incluí-la.

Circunscrever os "direitos da criança" a partir de uma rígida delimitação da infância segundo uma única descrição significa, também, abrir caminho para que muitos bonecos de pau não usufruam desses direitos. Se cairmos na tentação - de padres, metafísicos e cientistas - de fundamentar os direitos das crianças a partir da "verdade sobre o que é o menino de verdade", talvez a maior parte das crianças fique de fora das nossas conversas e, pior, dos nossos cuidados e preocupações (GHIRALDELLI, 2000).

10 Conforme redação do artigo 98 do Estatuto da Criança e do Adolescente, considera-se em situação de risco toda criança e adolescente que tiver os direitos reconhecidos pela lei ameaçados ou violados por ação ou omissão da sociedade ou do Estado, por falta, omissão ou abuso dos pais ou responsável, ou em razão de sua conduta. 
No tocante às crianças vítimas de violência sexual, é relevante tecer algumas observações quanto ao comportamento pós-traumático (Gabel, 1997, pgs. 59/69):

1) Com freqüência, o abuso sexual acontece no contexto de uma relação afetiva entre o autor e sua vítima, porém, o grau de maturidade sexual e intelectual dos envolvidos é severamente distante;

2) As crianças abusadas sentem o corpo como profanado, e apresentam queixas somáticas como mal-estar difuso, enurese e encoprese (sobre tudo nas crianças menores e nas que sofreram penetração anal), perturbações do sono;

3) As vítimas de cinco a dez anos podem demonstrar conhecimentos sexuais inadequados e cenas de coito;

4) Entre adolescentes, detecta-se a agressão sexual sobre outras crianças, especialmente no caso de meninos que sofreram agressões sexuais na pré-puberdade, enquanto que as meninas repetem a situação com um comportamento de sedução repetitivo.

Deste modo, o que parece ser, muitas vezes, a demonstração de um desvio da personalidade da vítima, assinalando-a como culpada por ter sido sexualmente violada, nada mais é do que o reflexo da violência que sofreu e a apresentação de uma resposta, como alternativa para sua sobrevivência enquanto indivíduo.

Para a tutela efetiva de crianças e adolescentes contra os abusos sexuais, faz-se necessário, no momento da aplicação da lei, se atentar para a condição de vítima, de ser em peculiar condição de desenvolvimento, a fim de não se isolar a concepção de infância para poucos "meninos de verdade" e muitas crianças marginalizadas da proteção do ordenamento jurídico.

\section{Referências}

BRASIL. Constituição (1988). Constituição da República Federativa do Brasil. Disponível em: <http://www.planalto.gov.br/ccivil_03/Constituicao/Constituiçao.htm>. Acesso em: 25 abr. 2010.

Decreto-lei $n^{\circ}$ 2.848, de 7 de Dezembro de 1940. Código Penal. Disponível em:

<http://www.planalto.gov.br/CCIVIL/Decreto-Lei/Del2848.htm>. Acesso em: 25 abr. 2010. 
. Lei $n^{\circ} 8.069$, de 13 de julho de 1990. Dispões sobre o Estatuto da Criança e do Adolescente e dá outras providências. Disponível em: <http://www.planalto.gov.br/ ccivil_03/Leis/L8072.htm>. Acesso em: 25 abr. 2010.

Lei $n^{\circ} 12.015$, de 7 de agosto de 2009. Altera o Título VI da Parte Especial do Decreto-Lei $n^{\circ} 2.848$, de 7 de dezembro de 1940 - Código Penal, e o art. $1^{\circ}$ da Lei $n^{\circ} 8.072$, de 25 de julho de 1990, que dispõe sobre os crimes hediondos, nos termos do inciso XLIII do art. $5^{\circ}$ da Constituição Federal e revoga a Lei ${ }^{\circ} 2.2 .52$, de $1^{\circ}$ de julho de 1954 , que trata de corrupção de menores. Disponível em:

<http://www.planalto.gov.br/ccivil_03/_Ato2007-2010/2009/Lei/L12015.htm>. Acesso em: 25 abr. 2010.

CALDEIRA, Laura Bianca. O conceito de infância no decorrer da história. Disponível em: <http://www.diaadiaeducacao.pr.gov.br/diaadia/diadia/modules/conteudo/busca.php? cx=013073312029960378645\%3Ao8ste8iycyi\&cof=FORID

$\% 3 A 10 \& i e=I S O-8859-1 \& q=$ CALDEIRA

\%2C+Laura+Bianca\&sa=Pesquisar\&siteurl=www.diaadiaeducacao.pr.gov.br\%2Fdiaadia \%2Fdiadia\%2Findex.php\%3FPHPSESSID\%3D2011041917101293\#1150>. Acesso em: 10 jan. 2011.

CURY, Munir (Coord.). Estatuto da criança e do adolescente comentado. 8. ed. São Paulo: Malheiros Editores, 2008.

DISQUE 100 recebe denúncias de abusos contra criança. Disponível em: <http://fantastico.globo.com/Jornalismo/FANT/0,,MUL1595224-15605,00-DISQUE+RECEBE+ DENUNCIAS+DE+ABUSOS+CONTRA+CRIANCAS.html>. Acesso em: 25 maio 2010.

ESTEFAM, André. Crimes sexuais: comentários à Lei 12.015/2009. São Paulo: Saraiva, 2009.

GABEL, Marceline. Crianças Vítimas de Abuso Sexual. São Paulo: Summus, 1997.

GHIRARDELI JUNIOR, Paulo. As concepções de infância e as teorias educacionais modernas e contemporâneas. Educação e Realidade, v. 4, n. 1, p. 45-58, dez./jan./jul. 2000.

GRECO, Alessandra Orcesi Pedro; RASSI, João Daniel. Crimes contra a dignidade sexual. São Paulo: Atlas, 2010.

GUSMÃO, Chrysolito de. Dos crimes sexuais: estupro, atentado violento ao pudor, sedução e corrupção de menores. 5. ed. Rio de Janeiro: Biblioteca jurídica Freitas Bastos, 1981.

MESTIERI, João. Do delito de estupro. São Paulo: Revista dos Tribunais, 1982.

MURTA, Eduardo Freitas; AMARAL, Ana Paula Martins do. Abuso de menores, vergonha explícita. In: SIMPÓSIOS TEMÁTICOS FAZENDO GÊNERO CORPO, VIOLÊNCIA E PODER, 8., 2008, Florianópolis. Anais... Florianópolis, 2008.

NUCCl, Guilherme de Souza. Crimes contra a dignidade sexual: comentários à Lei 12.015, de 7 de agosto de 2009. São Paulo: Revista dos Tribunais, 2009. 
PRADO, Luis Regis. Curso de direito penal brasileiro parte especial: arts. 121 a 249. 7. ed. São Paulo: Revista dos Tribunais, 2008. v. 2.

RIBEIRO, Marisa Marques; MARTINS, Rosilda Baron. Violência doméstica contra a criança e o adolescente. Curitiba: Juruá, 2009.

RIO GRANDE DO SUL. Tribunal de Justiça do Estado do. Apelação Crime № 70029688942 (Sétima Câmara Criminal). Apelante: Marcos Antônio Santana Silva. Apelado: Ministério Público. Relator: Naele Ochoa Piazzeta. Porto Alegre, 29 abr. 2010. Disponível em: <http://www.tjrs.jus.br/site_php/consulta/exibe_documento.php? ano $=2010 \&$ codigo $=688828>$. Acesso em: 19 maio 2010.

SEABRA, André Salame. Abuso sexual na infância. Disponível em:

$<$ http://www.existencialismo.org.br/jornalexistencial/andreseabraabusosexual.htm>. Acesso em: 19 maio 2010.

TEIXEIRA, Lumena Celi. 0 outro lado do espelho: a exploração sexual sob o olhar de adolescentes prostituídas. 2001. Dissertação (Mestrado em Psicologia Social) - Pontifícia Universidade Católica de São Paulo, São Paulo. 